\title{
BRIEF REPORT
}

\section{The Ascent of Mount Everest Following Radial Keratotomy}

\author{
Thomas H. Mader, MD; Lawrence J. White, MD; Dale S. Johnson, MD; Fred C. Barth, MPS \\ From the Alaska Native Medical Center, Anchorage, AK (Dr Mader), and the Cascade Eye \& Skin Centers, P C, Tacoma, WA (Dr White), \\ Longmont, CO (Dr Johnson), and Boulder, CO (Mr Barth).
}

Several articles have described visual changes in radial keratotomy (RK) patients exposed to high altitude. ${ }^{1-4}$ Great notoriety was associated with the deleterious visual changes suffered by Beck Weathers, MD, during his disastrous attempt to climb Mt Everest following bilateral RK surgery. ${ }^{5}$ While ascending Mt Everest in 1996, some years after successful RKs, Dr Weathers suffered visual changes that worsened with increasing altitude. Poor vision at approximately 27000 feet rendered him unable to safely ascend or descend. Left alone, he was forced to remain overnight at this altitude until he was finally able to blindly stumble into a high base camp. Although he survived the incident, he lost both hands to frostbite. In this brief report, we will describe the visual changes experienced by an RK climber who was able to successfully ascend Mt Everest in 1999, and we will briefly review the literature on this subject.

In 1985 , a 33-year-old male mountain climber underwent 20 and 16 incision $\mathrm{RK}$ in the right and left eyes, respectively, for the correction of -5.25 sphere and -3.75 to $1.00 \times 75$ diopters of myopia. In the initial years following RK, although he climbed to altitudes near 20000 feet, he noted no visual difficulties. In his early $40 \mathrm{~s}$, he found it necessary to use +1.25 diopter reading glasses for near vision after staying overnight above 15000 feet. These were no longer needed following descent below 5000 feet. A few years later, while in his mid 40s, he noticed a decrement in distant vision as well as near vision following exposure to altitudes above approximately 20000 feet. He described this as a fuzziness to distant objects, which cleared slightly when straining his eyes. Again, both distant and near vision returned to normal following descent to below 5000 feet. Because of his visual changes at high altitudes, he sought consultation with

Corresponding author: Thomas H. Mader, MD, 6550 Farpoint Dr, Anchorage AK 99507 (e-mail: farpointak@gci.net). an ophthalmologist prior to his ascent of Mt Everest. At that time, his cycloplegic refraction was found to be $+3.00+.50 \times 150$ degrees, right, and $+2.75+.50 \times$ 55 degrees, left. The ophthalmologist recommended +2.50 reading glasses as well as +3.00 glacier goggles as needed at altitude.

He began his ascent of Mt Everest in May 1999 at the age of 47. As anticipated, he noted no visual difficulties until staying overnight above approximately 12000 to 15000 feet, where he complained of some decrement in near visual acuity, which was corrected with +2.50 diopter reading glasses. Upon gradual exposure to altitudes above 20000 feet, he also noticed a mild decrease in distant visual acuity. This was slightly annoying but not incapacitating. He tried +3.00 glacier glasses at high altitude, which improved distant visual acuity but caused his eyes to ache when trying to see 10 feet or less in front of him. He chose not to use the lenses because of these difficulties. He was able to summit Mt Everest without correction and experienced only minor visual blurring and glare.

This patient's history illustrates the hyperopic (farsighted) shift seen in RK patients exposed to altitude as well as the effect of the gradual loss of accommodation associated with aging. Several reports have documented visual and refractive changes at high altitude in RK patients, ${ }^{1-4}$ and a mechanism has been proposed to explain these observations. ${ }^{6}$ Hypobaric hypoxia causes corneal edema, which creates a uniform stress on any cornea exposed to high altitude. Intact corneas thicken but do not change in curvature or refraction because of inherent structural stability. However, in RK patients, because of structural compromise in the area of the RK incisions, this area may preferentially expand. This circumferential peripheral corneal expansion may lead to central corneal flattening and a hyperopic (farsighted) shift in refraction. These changes are progressive with increasing altitude and have been described as mildly to severely incapacitating. ${ }^{2,5}$ It is important to note that approximately 24 
hours of exposure are necessary to cause a hyperopic shift and the associated visual changes. Thus, upon arrival to a high camp, an RK climber's vision may be unchanged, but the same climber may experience profound visual changes upon awakening the next morning. It has been suggested that the additive hypoxic stress brought about by lid closure during sleep may accentuate the visual changes. A warning regarding these potential altitude-induced visual changes in RK climbers was published in the medical literature in $1996 .{ }^{7}$ Two previous reports have described great variability in the RK cornea's response to altitude., ${ }^{2,3}$ It is difficult to precisely explain the wide spectrum of response of RK corneas to altitude exposure. The patient's age, accommodative amplitude, postoperative refractive error, and endothelial cell count as well as the depth, number, and length of RK incisions may play a role. Our current report suggests that with caution, some RK patients can successfully continue high-altitude mountaineering following RK. It might be prudent for RK climbers to consider the use of plus lenses at altitude and inform their climbing partners of their potential disability.

\section{References}

1. White L, Mader T. Refractive changes with increasing altitude after radial keratotomy. Am J Ophthalmol. 1993; $115: 821-823$.

2. Mader T, White L. Refractive changes at extreme altitude after radial keratotomy. Am J Ophthalmol. 1995;119:733737.

3. Mader T, Blanton C, Gilbert B, et al. Refractive changes during 72 hour exposure to high altitude after refractive surgery. Ophthalmology. 1996;103:1188-1195.

4. Creel D, Crandall A, Swartz M. Hyperopic shift induced by high altitude after radial keratotomy. J Refract Surg. 1997;13:398-400.

5. Krakauer J. Into Thin Air. New York: Villard; 1997.

6. Winkle K, Mader T, Parmley V. The etiology of refractive changes at high altitude after radial keratotomy: hypoxia versus hypobaria. Ophthalmology. 1998;105:282-286.

7. Mader T, White L. High-altitude mountain climbing after radial keratotomy. Wilderness Environ Med. 1996;7:77-78. 